\title{
Arias Montano, traductor: filosofía, técnicas y praxis multilingüe
}

\author{
Natalio Fernández Marcos \\ Emilia Fernández Tejero \\ ILC, CCHS - CSIC, Madrid
}

Arias Montano fue uno de los mejores orientalistas del siglo XVI. Es conocido especialmente como editor de la Políglota de Amberes. Tradujo al latín diversos originales de esa Políglota y en sus comentarios bíblicos ofreció una nueva traducción de la mayoría de los pasajes. Partidario de la versión literal, llegó incluso a corregir la traducción latina de Sanctes Pagnino. En sus comentarios bíblicos recurrió a giros y modismos de las lenguas europeas de su tiempo, en especial el castellano. En este artículo los autores comentan palabras, dichos y refranes castellanos que sirvieron a Arias Montano para ilustrar algunos pasajes. No incluyó entre sus proyectos el traducir la Biblia al español, pero a la luz de la sensibilidad lingüística que demuestra, los autores piensan que, de haberlo llevado a cabo, tal vez Arias Montano hubiera sido considerado como el mejor traductor de la Biblia al castellano.

Palabras Clave: Arias Montano; traducción; refranes castellanos.

Arias Montano, Translator: Philosophy, Techniques, and Multilingual Praxis.Arias Montano was one of the best orientalists of the $16^{\text {th }}$ century. He is specially known as editor of the Antwerp Polyglot. He translated into Latin several originals of this Polyglot, and in his Biblical commentaries he provided a new translation for most of the passages. He was in favour of a literal translation and he even dared to correct Sanctes Pagnino's Latin version. In his Biblical commentaries he utilized idioms of the European languages of his time, especially Castilian. In this article the authors comment these Castilian words, sentences and sayings used by Arias Montano to illustrate various passages. He did not include among his projects a Spanish translation of the Bible; but in the light of his linguistic sensitivity, the authors think that, if he would have done this version, he would possibly have been considered the best translator of the Bible into Spanish.

KEYwords: Arias Montano; Translation; Castilian Sayings.

\footnotetext{
*natalio.fernandez@cchs.csic.es, emilia.fernandez@cchs.csic.es
} 
Arias Montano es conocido - cuando lo es-como el mejor orientalista del siglo XVI español. Su edición de la Biblia Regia ${ }^{1}$ demuestra su saber y dominio de las lenguas bíblicas, aunque también pudo preciarse de conocer las principales lenguas modernas de la Europa de su tiempo. Sin embargo, Arias Montano no figura en las historias de la literatura española, a diferencia de su contemporáneo Luis de León. La razón es que no publicó ninguna obra en castellano; tampoco tradujo a esta lengua la Biblia ni los autores clásicos.

Se duda de la autoría de su incompleta paráfrasis al Cantar de los cantares $^{2}$. Desde luego, apreciaba las traducciones de la Biblia a lenguas vulgares o «familiares» -así las llamaba él mismo- como demuestra su interés en coleccionar Biblias romanceadas en su etapa de bibliotecario de El Escorial ${ }^{3}$.

Un afan pedagógico por acercar los originales de los textos bíblicos al público culto de su tiempo le llevó a limitar sus traducciones a la lengua común del Humanismo, el latín. Se cuidó de que los textos hebreo, arameo, griego y siriaco de la Políglota fueran acompañados de sus correspondientes traducciones latinas. Él mismo, además, tradujo al latín el Targum a Profetas Primeros.

\section{FILOSOFÍA DE LA TRADUCCIÓN}

En el «Prefacio a los libros de las paráfrasis caldeas y sus versiones» dice respecto a su traducción de los Profetas Primeros ${ }^{4}$ :

Al traducirlo preferimos el respeto religioso a la belleza de las palabras, tanto porque atendimos al beneficio de los principiantes

\footnotetext{
${ }^{1}$ F. Pérez Castro, L. Voet, La Biblia Políglota de Amberes (Madrid 1973); A. SCHENKER, «The Polyglot Bibles of Antwerp, Paris and London: 1568-1658», en M. Saeb $\varnothing$ (ed.), Hebrew Bible / Old Testament. The History of Its Interpretation, vol. II: From the Renaissance to the Enlightenment (Göttingen 2008) págs. 774-784.

${ }^{2}$ L. M. Gómez Canseco, V. NúÑez Rivera, Arias Montano y el Cantar de los Cantares: estudio y edición de la Paráfrasis en modo pastoril (Kassel 2001).

${ }^{3}$ S. FERNÁNDEZ LóPEZ, Lectura y prohibición de la Biblia en lengua vulgar. Defensores $y$ detractores (León 2003) págs. 280-285.

${ }^{4}$ Seguimos, en general, la traducción de M. A. Sánchez Manzano, Prefacios de Benito Arias Montano a la Biblia Regia de Felipe II (León 2006); en adelante, Prefacios. En ocasiones, el cotejo con el latín de su edición bilingüe nos ha llevado a matizar la traducción de algún pasaje.
} 
en el idioma caldeo, con el criterio de traducir palabra por palabra, figura retórica por figura y locución por locución [...] ante todo porque siempre hemos estimado mucho más en los textos sagrados dar el verdadero sentido, original de esa lengua de la que traducimos, y tener un conocimiento cierto de su propiedad y de sus características, antes que buscar el ornato y la elegancia de aquella a la que traducimos. Pues no sólo hay que observar por encima de todo qué ha dicho el Espíritu Santo, y sus profetas, ministros e intérpretes, sino cómo se ha dicho, y la elocución de su portavoz no ha de ser analizada en la elocuencia del traductor [...]. Aquella cita conocida Como traductor fiel no pretendas traducir a la letra [Jerónimo, carta 57,5] no tiene tanta autoridad que tenga cabida en los textos sagrados, ni se refiere a los que vierten textos ajenos a otra lengua, sino que atañe principalmente a aquellos que componen su obra a partir de un poema de otro o de otra obra, pero en otro género literario, y escriben tragedias o comedias a partir de leyendas épicas [...] nosotros tenemos el criterio de que consideramos que los que vayan a traducir de lenguas extranjeras y de las antiguas a otras lenguas tienen que tener en cuenta [...] la indicación exacta de las figuras y la imitación del lenguaje metafórico, y por fin, el valor equivalente de las palabras indeclinables -según dicen- de las lenguas antiguas con toda la fidelidad que sea posible [...]. Por tanto, quien nos exija elegancia de la lengua latina escrupulosamente, sepa que no nos hemos propuesto cuidar las palabras, sino que nuestra única intención en nuestra actividad es simplemente cuidar la verdad ante todo ${ }^{5}$.

No era, sin embargo, desconocedor de las dificultades inherentes a toda traducción, lo que justifica sus críticas y correcciones a la Vulgata y a la traducción de Pagnino. Por ejemplo, advierte que un verbo ambiguo no siempre se puede traducir ambiguamente, sino que el significado de la palabra queda recogido en la traducción sólo en parte y no por entero. Ese tipo de palabras tiene dos acepciones o sentidos que reclaman una interpretación. Así comenta la palabra nedabot (Sal 110,3):

\footnotetext{
${ }^{5}$ Sin embargo, al igual que Jerónimo, no fue del todo coherente con respecto a la literalidad de las traducciones. Después de traducir los libros de Josué y Jueces conforme a este criterio, en otros libros como Reyes, se mostró más liberal frente al hebreo, para suavizar posibles asperezas y conseguir un latín más pulido y refinado. Prefacios, págs. 65-69.
} 


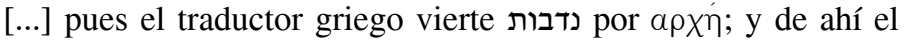
latino traduce principio, cuando debía haber traducido principado, pues en esta palabra precisamente se contiene el gran misterio del imperio y la autoridad de Cristo ${ }^{6}$.

Admite que las diversas lenguas tienen estructuras diferentes, que en la Escritura hay con frecuencia palabras de doble sentido; más aún, que la lengua santa

[...] adelanta a todas las demás, y tiene expresiones que contienen en sí un significado múltiple, casi infinito, que no vas a encontrar en cualquier otro género de lenguas [...]. Y hay que creer que sobre todo por esta razón fue elegida por Dios, por ser la más fecunda de todas, para que fuera como un sagrario de los misterios divinos ${ }^{7}$.

Siguiendo la tradición de traducciones literales, palabra por palabra (Áquila, Ferrara, Pagnino) llega a concluir:

[...] que gran número de traductores de nuestro tiempo están enteramente por hacer la Biblia hebrea lo más latina que se pueda, es decir, que se preocupan solamente por el estilo latino, ellos [los defensores de las traducciones literales] por el contrario sólo se fijan en tener la Biblia hebrea, no lo más latina que se pueda, sino en latín lo más hebrea que se pueda, esto es, que no se aparte de la sintaxis y de la propiedad de la lengua hebrea, ni un dedo, como se suele decir ${ }^{8}$.

Todo esto es aplicable a sus traducciones al latín del Antiguo Testamento o Biblia Hebrea. Respecto al Nuevo Testamento, escrito en griego, siguió la misma filosofía de traducción interlineal palabra por palabra, con la diferencia de que en el Antiguo Testamento la versión latina resultante es una corrección de la traducción de Pagnino, mientras que en el Nuevo Testamento es una corrección de la traducción de la Vulgata.

Atreverse a corregir la Vulgata era una postura que implicaba riesgos, puesto que la Vulgata era el texto oficial de la Iglesia. Los humanistas de la época debían sentirse atemorizados ante las reglas estrictas con las que

\footnotetext{
${ }^{6}$ Prefacios, pág. 89.

${ }^{7}$ Prefacios, pág. 91.

${ }^{8}$ Prefacios, pág. 93.
} 
la Iglesia protegía el texto y la intepretación de la Vulgata. La Inquisición española pesaba, aunque fuera de forma subconsciente, sobre la conciencia de los intelectuales y oscurecía el trasfondo de cualquier pensamiento independiente, de la menor disidencia. De ahí, el que Arias Montano, en el «Prefacio [...] a la traducción latina del Nuevo Testamento griego» se sintiera obligado a justificarse una y otra vez por su atrevimiento. Se nos manifiesta como un hombre dividido entre las exigencias de sus conocimientos filológicos y sus continuas protestas de fidelidad a la Iglesia y su respeto hacia la Vulgata. Se interpreta como una manifestación de esa fidelidad y respeto el hecho de que a lo largo de todo el Antiguo Testamento de su Biblia interlineal pusiera una cruz antes de cada versículo, actitud que Ch. D. Ginsburg calificó de «desenfrenada» y que impedía a los judíos el acceso a esa espléndida edición".

[...] nos propusimos, no corregirla y posponerla a las demás, sino explicarla mejor con la ayuda de las otras [...]. También se añade a esto la traducción de muchos lugares, que añadida a la edición Vulgata, ayuda mucho a la comprensión del sentido. De esta manera, nos hemos ocupado de que escribieran nuestra traducción latina del Nuevo Testamento entre las líneas del texto griego, para que cualquier frase latina se corresponda con la griega escrita debajo. Pero cuando la Vulgata no se desvía en el sentido -aunque alguna vez ocurra-, sino que se desvía de la propiedad de las expresiones griegas, se encuentra colocada en el margen, escrita con caracteres latinos en tanto que la sustituimos por nuestra versión literal con caracteres itálicos, de manera que hemos dejado la Vulgata íntegra y hemos traducido la versión griega palabra por palabra [...] nuestro propósito no ha sido corregir ni enmendar la edición Vulgata y antigua, pues hemos considerado -según hemos dicho más arriba- que debía preferirse siempre a todas las demás, con tal que se pueda mantener íntegra y sin corrupción, sino que nuestro propósito fue traducir la expresión griega de la manera más adecuada ${ }^{10}$.

${ }^{9}$ Ch. D. Ginsburg, Introduction to the Massoretico-Critical Edition of the Hebrew Bible (London 1987) págs. 107-108; «As far as the Jews were concerned he precluded the possibility of their using this splendid edition with the interlinear Latin translation, because he wantonly placed the sign of the Cross at every verse-division throughout the whole Hebrew text».

${ }^{10}$ Prefacios, págs. 73-77. 


\section{TÉCNICAS}

\section{Su versión del Antiguo Testamento}

No se trata de una versión nueva, sino de una revisión de la traducción de Sanctes Pagnino.

A pesar de las alabanzas que Arias Montano prodigó a esta traducción en numerosas ocasiones, especialmente por su literalidad, pensaba que se podía mejorar. Sus objeciones principales eran:

- que en muchos lugares la interpretación de Pagnino no se correspondía con la verdad hebrea;

- que traducía parafrásticamente, olvidando que estaba comprometido con una traducción literal;

- que, a menudo, incluía adiciones innecesarias;

- que no se ajustaba a los misterios de la fe católica; apoyó esta crítica aduciendo diversos pasajes, que podrían ser traducidos con mayor exactitud, entre ellos el conocido de Job 19,25-26. En la Vulgata hay una declaración afirmativa de la resurrección:

Vulgata: «pues sé que mi redentor vive y en el último día resucitaré de la tierra» ${ }^{11}$.

Pagnino traduce: «yo he conocido a mi redentor vivo y renovado, que asciende de la tierra» ${ }^{12}$.

Arias Montano: «Yo sé que en el último día voy a resucitar» ${ }^{13}$.

Lo curioso es que ninguna de las tres traducciones responde al original hebreo: «Yo sé que mi go’el está vivo y al final sobre el polvo se alzará» ${ }^{14}$.

${ }^{11}$ Scio enim quod redemptor meus vivat [mss. vivit] et in novissimo de terra surrecturus sim. R. WeBER, Biblia Sacra iuxta Vulgatam versionem (Stuttgart 1975).

${ }^{12}$ Et ego novi redemptorem meum vivum et novissimum, qui super terram surget. Prefacios, págs. 94-95.

${ }^{13}$ Ego scio quod in novissimo de terra surrecturus sum. Prefacios, págs. 94-95.

14 ואני ידעתי גאלי חי ואחרון על עפר יקום. Biblia Hebraica Stuttgartensia (Stuttgart 1987). La palabra hebrea go'el alude a una institución de Israel, según la cual el pariente más próximo a un hombre que fallece debe hacerse cargo de sus posesiones, y casarse con la viuda si ésta ha quedado sin hijos. 


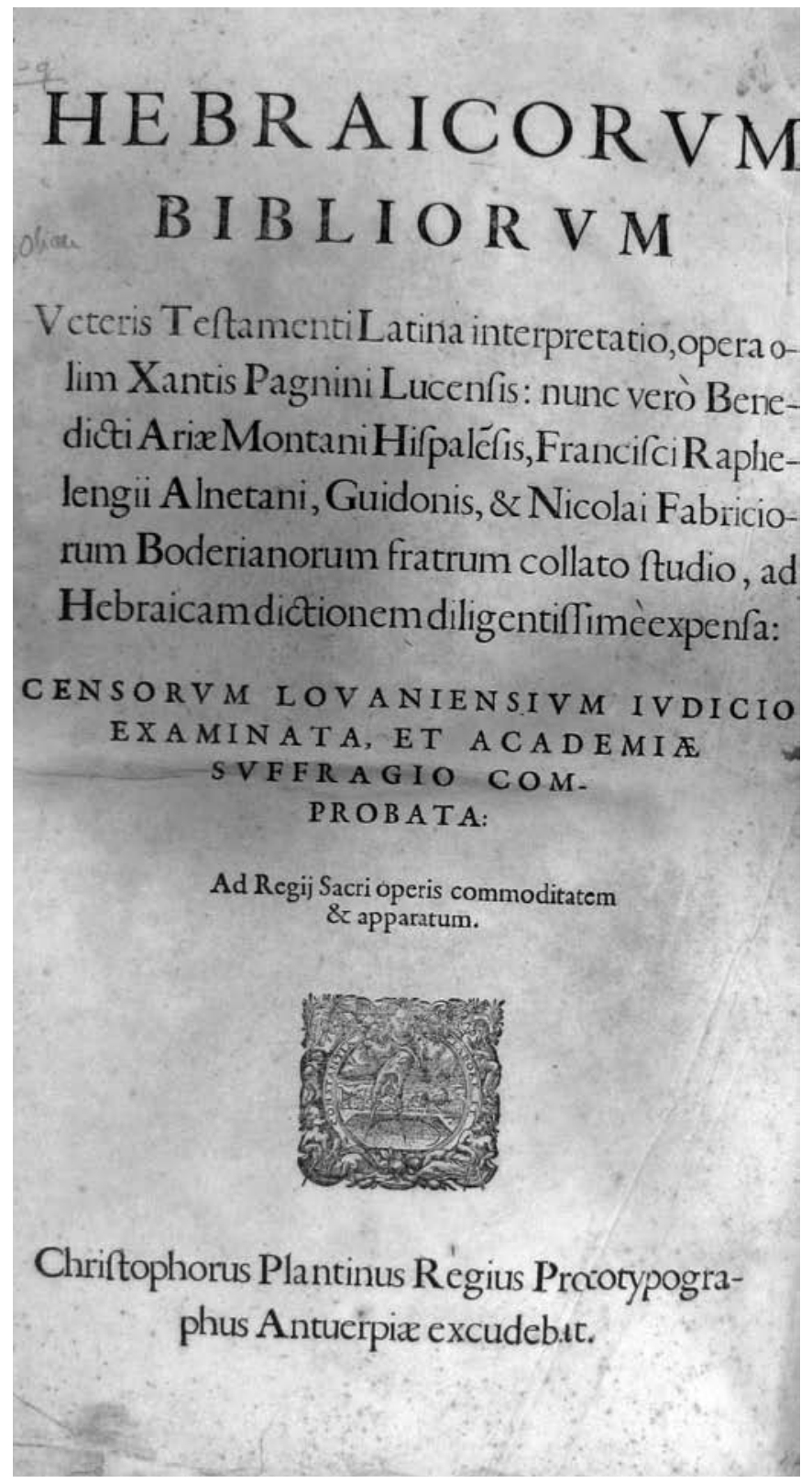

Figura 1: Hebraicorvm Bibliorvm (texto hebreo con versión interlineal latina), Antuerpiae 1572: portada. 


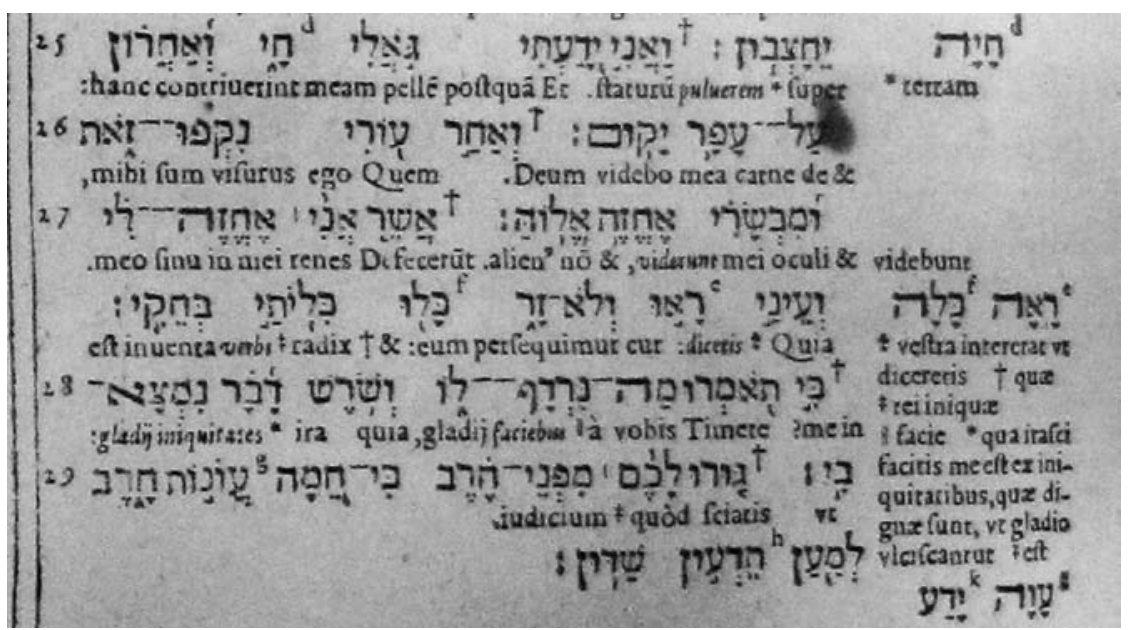

FIGURA 2: Hebraicorvm Bibliorum: Job 19, $25-27$ (detalle).

Es un caso evidente en el que los conceptos dogmáticos basados en la Vulgata prevalecieron sobre los criterios filológicos en Arias Montano, por mucho que se preciara de ser un traductor más literal que Pagnino. De hecho, la traducción de este último está más ajustada al hebreo. En el oficio de difuntos de la liturgia cristiana se utilizó el texto de la Vulgata hasta el Concilio Vaticano II.

Como Felipe II no le permitió utilizar la versión de Pagnino para la columna latina de la Biblia Regia, Arias Montano consultó a la Universidad de Lovaina con la finalidad de que, partiendo de la traducción del mismo Pagnino, se le permitiera llevar a cabo una nueva más ajustada a las características de la lengua hebrea. Los censores aceptaron su propuesta por el conocimiento de lenguas que tenía Arias Montano. Sin embargo, esa traducción no fue publicada como columna hebrea de la Políglota, sino como volumen aparte y separada del resto del Apparatus.

El modo como procedió fue el siguiente:

Finalmente hemos compuesto toda la obra de modo que hemos sustituido la versión de Pagnino por la nuestra literal, impresa con otra clase de caracteres, a saber, en itálico, y la hemos colocado en el margen de manera fidedigna, para que se pueda ver claramente 
con esa diferencia de letra y con las notas escritas al margen lo que hemos desechado y lo que hemos cambiado.

Hemos conseguido con nuestro trabajo que nadie tenga que esforzarse para confrontar las expresiones hebreas con las latinas, puesto que cada una de las latinas se corresponde con cada una de las voces hebreas en su lugar, de forma que de un golpe de vista se puedan leer y comparar al mismo tiempo el texto hebreo y el latino, a semejanza de quienes de un golpe de vista cantan cantilenas musicales, distintas de las notas, siendo dependientes y anexas a ellas. También los temas difíciles de ciertos verbos, que llaman raíces, están escritos al margen, para que de este modo se pueda acudir con mayor seguridad al léxico o al diccionario, sin que quede ningún resquicio de duda o de interpretación ${ }^{15}$.

Sin embargo, hay que subrayar que al colacionar la traducción de Pagnino con el original hebreo, se percibe que no es tanta la literalidad como se ha dicho en numerosas ocasiones. Y, lo que es más, que las correcciones de Arias Montano a Pagnino tampoco se ajustan del todo a la extrema literalidad de la que presume en los Prefacios a la Biblia Regia. Pero, sería un anacronismo el aplicar criterios modernos de literalidad a los humanistas del siglo XVI quienes, por otra parte, fueron pioneros en tantas áreas de las ciencias bíblicas.

Literal sí, pero con ciertos límites. Se comportó, sin embargo, de manera distinta, en sus comentarios a los libros bíblicos.

\section{Su versión del Nuevo Testamento}

Procedió de forma similar al editar el Nuevo Testamento, como señalamos anteriormente: sustituyó la Vulgata por su propia traducción en cursiva cuando consideraba que no era fiel al texto griego y colocó en el margen el texto original de la versión de Jerónimo.

- Buscó coherencia interna, al conservar, siempre que pudo, la misma palabra latina para la misma palabra griega, por ejemplo, tradujo

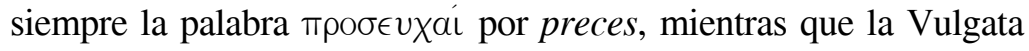
unas veces traduce preces y otras oratio.

\footnotetext{
${ }^{15}$ Prefacios, págs. 99-101.
} 


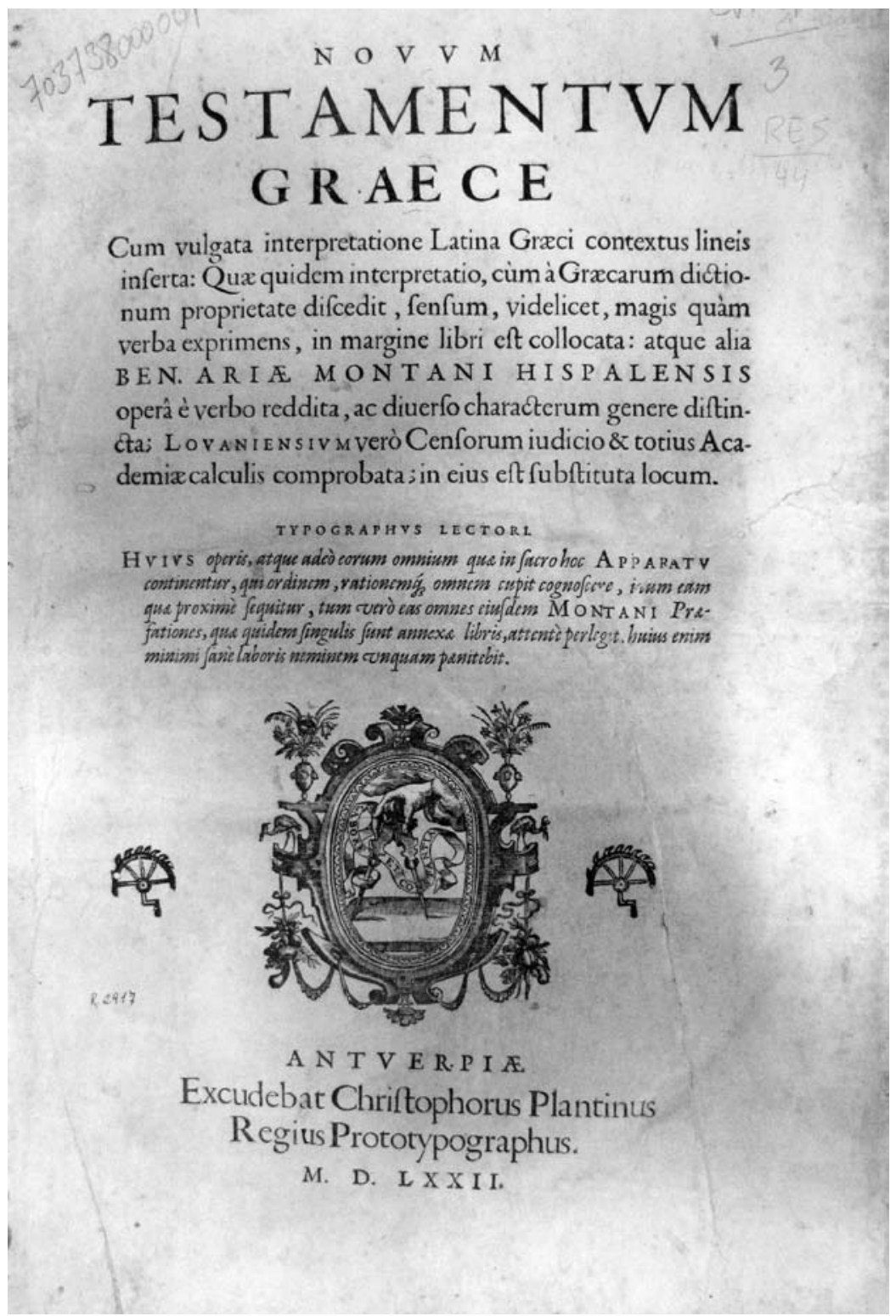

Figura 3: Novum Testamentum Graece (texto griego con versión interlineal latina), Antverpiae 1572: portada. 


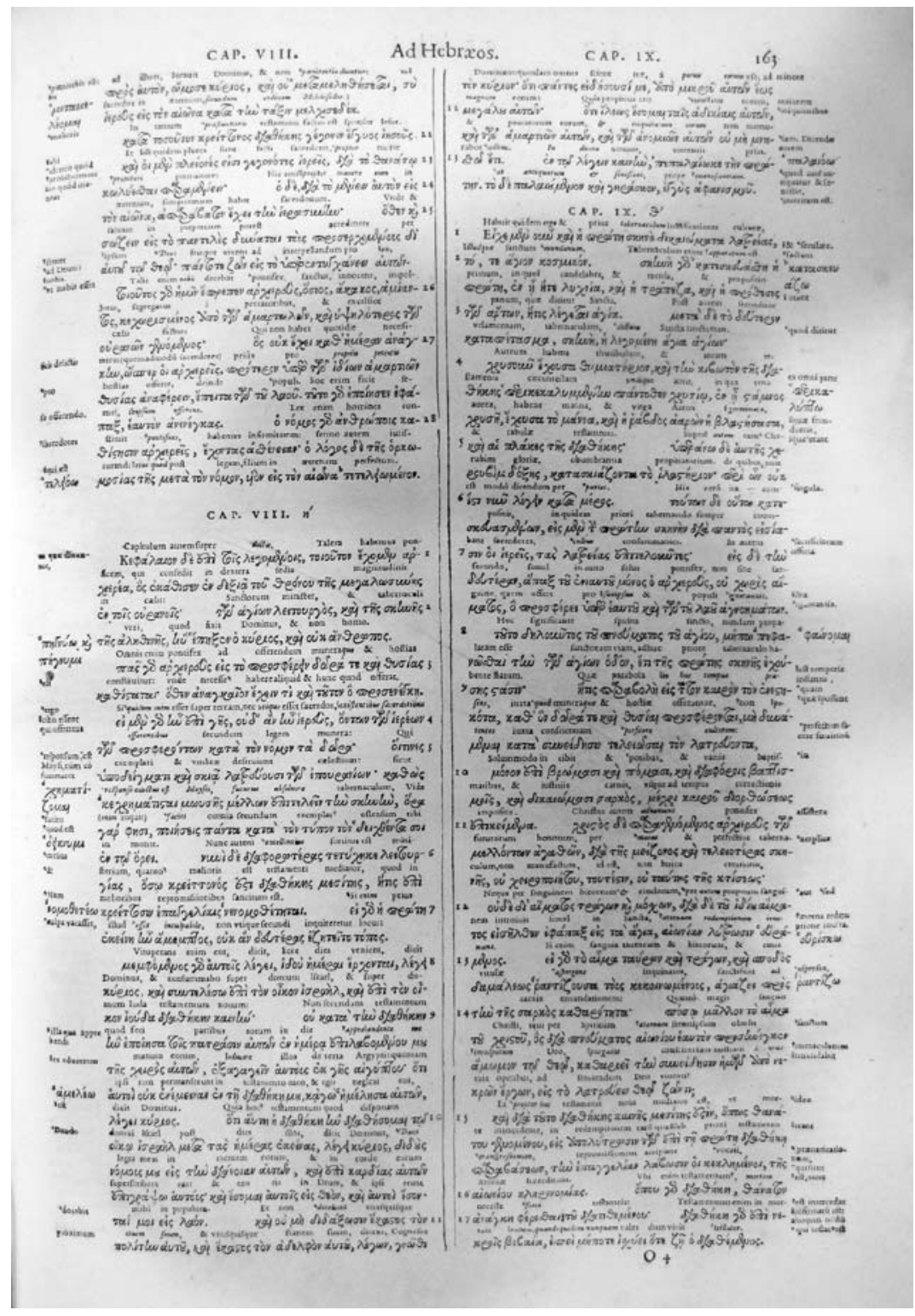

Figura 4: Novum Testamentum Graece: Carta a los Hebreos 7,21-9,17 (detalle). 
- Acuñó neologismos para mantener el significado exacto del griego: sobre la traducción a Filipenses 3,4 afirma: «hemos traducido $\pi \epsilon \pi \circ \dot{\theta} \theta \eta \sigma \iota \nu$, por confisibilitatem» ${ }^{16}$, a partir de confisus, y el sufijo -bilis que implica posibilidad, para distinguirla de confidentia.

- Tradujo los artículos griegos por pronombres latinos: en 2 Pedro

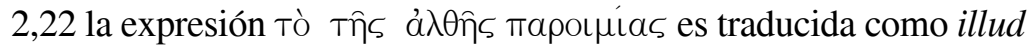
veri proverbii.

- Intentó también reflejar los tiempos y modos griegos en latín, traduciendo los participios griegos por participios latinos.

Sin embargo, advirtió seriamente que esta traducción nunca fuera impresa por nadie separada del texto griego ${ }^{17}$.

\section{Sus traducciones latinas en los comentarios bíblicos}

Arias Montano escribió comentarios a varios libros del Antiguo Testamento. Conservamos los comentarios a Isaías, a los Profetas Menores, a los treinta y un primeros Salmos, a Josué y a Jueces.

En estos comentarios utilizó como lema el texto de la Vulgata; pero en el desarrollo del comentario recurrió a todos los procedimientos filológicos a su alcance para reproducir el sentido literal del hebreo: utilizó las versiones antiguas, en especial la aramea y la griega, e incluso recurrió a las lenguas modernas para explicar y afinar el sentido de determinadas expresiones. Y, lo que es más interesante, dio su propia traducción al latín del texto hebreo, discrepando en la mayoría de los casos de la Vulgata.

Es aquí dónde vemos con mayor claridad la puesta en práctica de su filosofía y sus técnicas de traducción. A diferencia de las traducciones interlineales editadas en la Políglota, en este caso se sintió liberado de la secuencia interlineal, y de las plantillas de la Vulgata y de la edición de Pagnino. Su traducción latina en los comentarios no suele coincidir ni siquiera con sus propias correcciones a la interlineal de Pagnino.

${ }^{16}$ Prefacios, pág. 79. En este caso, su afirmación del Prólogo no se cumple en el texto de la interlineal, donde aparece la palabra confidentiam de la Vulgata, sin corrección alguna al margen.

${ }^{17}$ Prefacios, págs. 77-81. 
Para subrayar que ofrecía su propia traducción utilizó expresiones como: Hebraice, Hebraice ad verbum sic habet, Ex primaeva lingua, ex verbo, Ex Hebraico sic Latine sonat, In sacra lingua sic, etc. Con este método, al menos en algunos libros, consiguió dar prácticamente una nueva traducción latina.

Vamos a analizar algunos ejemplos, tomados de su comentario al libro de Jueces ${ }^{18}$.

\section{1,1}

Vulgata: Quis ascendet ante nos contra Chananaeum, et erit dux belli?

Arias Montano: Quis ascendet nobis ad Chananaeum initio ad praeliandum cum eo?

Texto masorético: «Quién subirá de entre nosotros contra el cananeo en primer lugar para combatir con él?» ${ }^{19}$.

\section{2,18}

Vulgata: Cumque Dominus iudices suscitaret, in diebus eorum flectebatur misericordia, et audiebat afflictorum gemitus, et liberabat eos de caede vastantium.

Arias Montano: Et cum constitueret Dominus illis iudices illos, et erat Dominus cum iudice illo, et servabat illos de manu hostium suorum omnibus diebus iudicis illius: quia poenitebat Dominum propter gemitum ipsorum, à facie affligentium eos, et opprimentium eos.

TM: «Cuando suscitó Yahweh para ellos jueces, estaba Yahweh con el juez, y los salvaba de la mano de sus enemigos todos los días del juez; porque se compadecía Yahweh de sus gemidos a causa de los que los afligían y los oprimían» ${ }^{20}$.

${ }^{18}$ De Varia Republica, sive Commentaria in librum Iudicum (Amberes 1592). Hemos traducido el hebreo de forma muy literal, aunque a veces resulte un castellano rudo; ayudará a apreciar mejor hasta qué punto la traducción de Arias Montano se ajusta al hebreo frente a la Vulgata.

מי יעלה לנו אל הכנעני בתחלה להלחם בו 19.

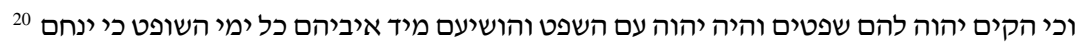
יהוה מנאקתם מפני לחציהם ודחקיהם ינחיהם 
4,24

Vulgata: Qui crescebant quotidie, et forti manu opprimebant Iabin, Regem Chanaan, donec delerent eum.

Arias Montano: Et procedebat manus filiorum Israel, procedere et durescere adversus Iabinum Regem Chanaan, quo ad exciderint Iabinum Regem Chanaan.

TM: «Y fue la mano de los hijos de Israel ir y dura sobre Yabín rey de Canaán, hasta que aniquilaron a Yabín rey de Canaán» ${ }^{21}$.

7,4

Vulgata: ... duc eos ad aquas, et ibi probabo illos: et de quo dixero tibi, ut tecum vadat, ipse pergat: quem ire prohibuero, revertatur.

Arias Montano: Demitte eos ad aquas, et ibi probabo ipsum tibi, et erit quem dixero tibi, hic ibit tecum apud te, is ibit apud te: et omnis quem dixero tibi, hic non ibit tecum, ipse non ibit.

TM: «Haz bajar a ellos al agua y los probaré para ti allí; y sucederá que diré a ti: ése irá contigo, él irá contigo; y todo el que diré a ti: ése no irá contigo, él no irá» ${ }^{22}$.

\section{1,31}

Vulgata: Quicumque fuerit primus egressus de foribus domus meae, mihique occurrerit revertenti cum pace à filiis Ammon, eum holocaustum offeram Domino.

Arias Montano: Et erit exiens quod exierit è foribus domus meae in occursum meum in meo reditu in pace à filiis Ammon, et erit Domino vel adscendere fecero illud holocaustum.

TM: «Y será que el saliente que salga de las puertas de mi casa a mi encuentro, en mi volver en paz de los hijos de Amón, será para Yahweh, lo sacrificaré, sacrificio» ${ }^{23}$.

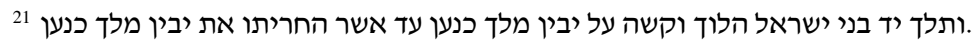

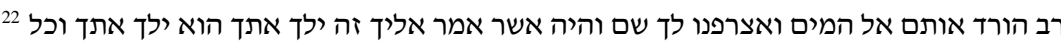

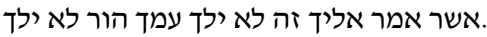

והיה היוצי אשר יצא מדלתי ביתי לקראתי בשובי בשלום מבני עמון והיה ליהוה והעליתהו 23 עולה
} 
15,16

Vulgata: In maxilla asini, in mandibula pulli asinarum delevi eos percussi mille viros.

Arias Montano: In maxilla HHAMOR HHAMOR HHAMORATHAIM, in maxilla HHAMOR percussi mille virum [En este caso, la sonoridad del hebreo le lleva a transcribir la aliteración del original, imposible de reproducir en la lengua latina $]^{24}$.

TM: «Con la quijada de un asno, un asno, dos asnos; con la quijada de un asno, maté a mil hombres» ${ }^{25}$.

Una sencilla comparación de los textos latinos pone de relieve las enormes diferencias entre la traducción de la Vulgata y la traducción de Arias Montano. Jerónimo remodeló la frase y logró un latín aceptable, recurriendo incluso a la paráfrasis para salvar el estilo y la armonía de la lengua término. Arias Montano, en cambio, fue tan fiel al hebreo, incluso en las repeticiones, el uso de la parataxis y el mantenimiento de los efectos sonoros del original, que no se preocupó para nada de la elegancia del latín.

\section{Praxis multilingüe}

Hasta aquí algunos ejemplos de las formas que tuvo Arias Montano de abordar, tratar e incluso corregir los textos bíblicos latinos de la Biblia Regia, y de cómo en sus comentarios bíblicos hizo su propia traducción literal del texto hebreo al latín.

\footnotetext{
${ }^{24}$ En la Biblia de Alba (1422-1430) la traducción es: «con una quixada de un asno fize monton e montones de omnes, que con una quixada de asno tengo muertos mil omnes»; en la Biblia de Ferrara (1553): «con quixada del asno a monton de montones: con quixada del asno heri mil varones». En las traducciones modernas encontramos distintos grados de aproximación a los efectos sonoros del original. F. CANTERA - M. IgLESIAS, Sagrada Biblia (Madrid 2003, $3^{\text {a }}$ ed.): «Con la quijada de un asno bien los he arreado, con la quijada de un asno a mil hombres he matado»; L. A. SchöKel - J. MAteos, Nueva Biblia Española (Madrid 1977, 20 ed.): «Con la quijada de un burro, zurra que zurro, con la quijada de un burro maté a mil hombres».
}

בלחי החמור חמור חמרתים בלחי החמור הכיתי אלף איש 25. 
Pero también se encuentran diseminados a lo largo de sus comentarios palabras, dichos y refranes en las lenguas europeas de su tiempo, especialmente en castellano.

Ya dedicamos un artículo a Arias Montano como traductor de topónimos, tomados todos ellos de su comentario latino al libro de Josué. Recordemos algunos: 'Nidada', 'Fuen cerrada', 'Casa guarida', 'Redondela', 'Alhama', 'Cervera', 'Higuera de Silo' ${ }^{26}$.

Veremos ahora ejemplos de otros tipos, tomados fundamentalmente del comentario latino al libro de Jueces, y extraídos algunos otros de los comentarios a Josué y Profetas Menores.

Hemos encontrado dispersas expresiones tales como 'hogaça', 'quartal', 'atalaya', 'aventureros', 'fuero', 'raodal, raudal', 'casamiento', 'cabos', 'estrañaron', 'cuesta, cumbre', 'puerta', 'a poco mas o menos', 'à hecho', 'sazon', 'cuerpo de guardia', 'tripa', 'nata'.

Expresiones en otras lenguas, como francés: 'Ie vous le remercieray', 'ce que estoit son retraict', 'en ceste mesmes saison', 'en ce saison icy', 'une faute ainsi que cela ici', 's'en retirer bellement, et en ordre', 'pensez sur cela, et parlez les uns avec les autres'. Italiano: 'stropiato', 'fracasso di pan d'orzo', 'passa, passa', 'li figlioli guasti'. Belga, 'hy komts morghens vroech'. Portugués: 'moços'. Incluso recurre a varias lenguas simultáneamente: 'quercia, eycke, roble', 'Sacco sacco, Sanctiago Sanctiago, Spaña Spaña, Francia Francia, spada spada, fuego fuego, à Dio à Dio, bon viage bon viage'; 'a ellos, à ellos; mata, mata; caccia, caccia; dai, dai; courage, courage; hardiment, hardiment; chefs, cabos, capi' .

Los ejemplos de palabras o frases cortas en lenguas modernas podrían multiplicarse. Veamos ahora algunos ejemplos de sentencias y refranes que revelan la sensibilidad lingüística de Arias Montano tanto por lo que se refiere a la lengua origen como a la lengua término.

En el capítulo catorce del libro de Jueces se narra el matrimonio de Sansón con una filistea. Durante el banquete de celebración propuso un enigma a los asistentes: «Del que come salió comida y del fuerte salió dulzura» $(14,14)$. Se refería a un león al que había despedazado y en cuya boca encontró más tarde un panal de miel. Ante la imposibilidad de descifrar el

${ }^{26}$ N. Fernández Marcos y E. Fernández Tejero, «De 'Elteqeh a Hita», en E. Romero (ed.), Judaísmo Hispano. Estudios en memoria de José Luis Lacave Riaño (Madrid 2002) vol. I, págs. 255-264. 
enigma, los jóvenes filisteos desafiados convencieron a la mujer de Sansón de que le sonsacase, y así pudieron adivinarlo: «¿Qué es más dulce que la miel y qué es más fuerte que un león?». A lo que Sansón respondió: «Si no hubieseis arado con mi novilla no habríais descifrado mi enigma» $(14,18)$. Arias Montano, intenta reproducir la construcción y los efectos sonoros del original ${ }^{27}$, y traduce así: «Si con mi novilla non labraras, Mi cosicosilla non fallaras» ${ }^{28}$, expresión que no ha sido mejorada ni siquiera por el más ingenioso de los traductores de la Biblia al español, Luis Alonso Schökel ${ }^{29}$.

En el capítulo quince se narra una serie de proezas de Sansón contra los filisteos. En una de las confrontaciones $(15,8)$ dice el hebreo literalmente: «Y les hirió pierna sobre muslo, una herida grande $»^{30}$, hebraísmo que significa, por metonimia, la totalidad del cuerpo. Arias Montano traduce: «Dava en ellos quando arriba, quando abaxo, quando en pierna, quando en anca» ${ }^{31}$, imitando el modismo hebreo y buscando, como él mismo dice, poner de relieve la rapidez, la destreza, el golpe atinado y la imagen de los heridos que caían o huían de forma tan viva como si estuviera pintada ${ }^{32}$.

Arias Montano también recogió una serie de refranes o dichos castellanos que no son traducción del texto hebreo pero que le sirven para ilustrar la interpretación del pasaje que comenta.

En Jueces 19,14-21 se narra la acogida que ofreció un hombre de Guib'á un levita, a su concubina, a sus criados y a sus asnos. Al ofrecerle alimentos $(19,19)$, Arias Montano introduce el proverbio español, «Pan y vino anda el camino» y glosa el versículo 20 expresando el texto original a la manera

27 לולא חרשתם בעגלתי לא מצאתם חידתי.

${ }^{28}$ De Varia Republica, pág. 529.

${ }^{29}$ SchÖKEL - Mateos, Nueva Biblia: « Si no hubierais arado con mi novilla, no habríais acertado mi acertijo»; CANTERA - IGLESIAS, Sagrada Biblia: «Si no hubieseis arado con mi novilla, tampoco habríais descifrado mi enigma!». Biblia de Alba: «sy non aradades con la mi bezerra, vos non sopierades la mi proposiçion»; Biblia de Ferrara: «si no ararades con mi bezerra no hallarades mi divinacion».

30 ויך אותם שוק על ירק מכה גדולה.

${ }^{31}$ De Varia Republica, pág. 535.

${ }^{32}$ En la Biblia de Alba encontramos la siguiente traducción y glosa: «e firio las anchas e piernas muy grand ferida. Alguna glosa es que pone tanto qier dezyr como asy a los de cavallo como a los de pie»; la Biblia de Ferrara recoge esta interpretación: «y hirio a ellos peones con cavalleros ferida grande». CANTERA - IgLesias, Sagrada Biblia: «Y les causó de arriba abajo, una gran derrota»; ScHÖKEL - MATEOS, Nueva Biblia: «Y les sacudió una paliza». 
en la que podría decirse en español: «Seais muy bien venido, y lo sereis en mi casa: donde yo me encargo de lo que os faltare, aun que no sea mas que no dexaros trasnochar en la plaça». En el versículo 21, al comentar «echó pienso a los asnos», para justificar por qué atendió a los animales antes que a las personas, explica que es un signo de humanidad y aduce el proverbio español: «Quien bien quiere abeltran, bien quiere a su can» ${ }^{33}$.

También hay ejemplos similares en otros libros. Así, en el comentario a Josué, en el capítulo 13 en el que se trata de la partición del país entre las tribus de Israel, al enumerar los lotes correspondientes a la tribu de Rubén en el versículo 19, comenta: «En cada villa su maravilla» ${ }^{34}$.

En 24,11, al traducir el hebreo «los habitantes de Jericó», ba alê Yerîḥ̂̂ ('amos de Jericó'), comenta que en español la palabra ba 'al puede traducirse por 'amo, dueño', en italiano por 'patrone', y en alemán por 'meister', y lo ilustra con los siguientes refranes: «este negocio tiene dueño» $\mathrm{y}$ «donde no esta su dueño esta su duelo» ${ }^{35}$.

En el capítulo 24, Josué, con palabras de Yahweh, repasa brevemente la historia de Israel. En el versículo 13 se dice: «viñas y olivos que no plantasteis, vosotros comeis». Arias Montano lo glosa: «La viña el viejo la pone y el viejo la vendiña» ${ }^{36}$.

En 24,26, para corroborar la expresión «esta piedra servirá de testimonio contra vosotros, pues ella ha oído todas las palabras que Yahweh nos ha dicho», cita testimonios de los clásicos como Juvenal y Horacio quienes con frecuencia usan la prosopopeya, y lo confirma con el proverbio español: «Los montes han ojos, y las paredes oydos» ${ }^{37}$.

También en su comentario a Profetas Menores se pueden encontrar ejemplos similares.

${ }^{33}$ De Varia Republica, pág. 633. Posible errata de imprenta; debería decir «a beltran», como puede comprobarse en Refranes o proverbios en romance, que coligio, y glossò el Comendador Hernán Núñez, professor de Retórica, y Griego, en la Vniversidad de Salamanca (Lérida 1621), pág. 101. La primera edición de esta obra fue en Salamanca 1555.

${ }^{34}$ De Optimo Imperio sive in Lib. Iosuae Commentarium (Amberes 1583) pág. 392.

${ }^{35}$ De Optimo Imperio, pág. 655.

${ }^{36}$ De Optimo Imperio, pág. 665. Posible errata de imprenta por «y el mozo la vendiña».

${ }^{37}$ De Optimo Imperio, pág. 696. 
En Amós 3,11, entre las amenazas a los israelitas se dice: «el enemigo cercará la tierra $»^{38}$. Arias Montano lo califica de oración elíptica, pero lo justifica porque la fuerza y el ímpetu del que habla son tanto más vehementes cuanto más breves y escasas son las palabras que usa en la frase. Está glosando el término hebreo șar ('enemigo'), palabra de una sílaba, y lo compara al ímpetu de interjecciones españolas usadas en casos de peligro o ira: «fuego, rayo, landre [...] que loqueme, que lo parta, que le venga» ${ }^{39}$.

Amós 4,2 es una invectiva del profeta contra las damas samaritanas que oprimen a los pobres y maltratan a los indigentes. El profeta las llega a calificar de «vacas del Basán», las amenaza con la llegada de días en los que serán conducidas con ronzales y su posteridad, con anzuelos de pesca ${ }^{40}$. La Vulgata traduce esta última parte como et reliquias vestras in ollis ferventibus. Arias Montano, no contento con esta traducción, da la suya propia: et novissima vestra in ollis piscium. Comenta el duro futuro que les espera, comer alimentos viles, in ollis piscium, y menciona el dicho hispano «y vuestro paradero en ollas de pescado» ${ }^{41}$.

En Miqueas 1,11, un texto oscuro en hebreo, aparecen los nombres de varias ciudades, como Șa'anán y Bet-ha 'Eșel; el versículo finaliza con la palabra 'amdato ('su apoyo'). Estas tres palabras, según la Vulgata y Arias Montano, tienen una cierta conexión que, según la etimología popular, podrían traducirse como 'salida, vecindad y estabilidad'. Arias Montano ilustra el fenómeno con un caso similar que se da en español, y es que, como dice, en la provincia Bética, en el campo sevillano, casi en las estribaciones de los montes Marianos hay cinco ciudades vecinas que llevan los siguientes nombres: «Aracena, Cortegana, Almonester, Suffre, Cala». Y añade que, cambiando un poco la pronunciación, resulta la frase siguiente que los habitantes del lugar utilizan a modo de proverbio «non sine sale: Almenester sufre y calla y ara y cena, y corta de gana». Para demostrar que esa gracia desaparecería de traducirse a otras lenguas, hace la prueba con el latín: In inopia ferto et taceto, arato, et caenabis, secabisque libenter ${ }^{42}$.

\footnotetext{
38 צר וסביב הארץ.

${ }^{39}$ Commentaria in duodecim Prophetas (Amberes 1583) pág. 289. Posible errata tipográfica por «lo queme».

40 ואחריתכן בסירות דוגה.

${ }^{41}$ Commentaria, pág. 296.

${ }^{42}$ Commentaria, pág. 478.
} 
En la plegaria y salmo del capítulo tercero de Habacuc, se dice al final del versículo 17: «desaparecerá del aprisco el ganado menor y no habrá ganado mayor en los establos» ${ }^{43}$. Arias Montano comenta que a las ovejas les gustan los campos helados, mientras que los bueyes echan de menos las lluvias frecuentes, como se indica elegantemente con el proverbio hispano: «Si quiera lloniesse hasta que mi cuerno se remolleciesse: Si quiera elasse hasta que mi lana seme enhetrasse» ${ }^{44}$.

En el primer oráculo de Ageo se dice en el versículo 9: «esperar mucho y he aquí que poco» ${ }^{45}$, parataxis hebrea de uso frecuente. En este caso significa, según Arias Montano, que las cosas se van deteriorando con el tiempo y lo compara al proverbio español «Mirar a de lante y caminar paratras» ${ }^{46}$.

En las conminaciones a los sacerdotes del capítulo 2 de Malaquías se dice en el versículo 3: «[...] os echaré estiércol al rostro, el estiércol de vuestras fiestas» ${ }^{47}$. Arias Montano comenta que en las festividades se utilizaban para los sacrificios animales de mala calidad y pone la frase bíblica en relación con la española, referida a ese tipo de carnes: «Dio me vn estiercol de carne, que era para arrojarlo alas paredes» ${ }^{48}$.

\section{ConClusiones}

Gracias a la imprenta y a la atención que la Reforma prestó a los textos bíblicos, en el siglo XVI surgieron diversas traducciones de la Biblia a distintas lenguas vernáculas, algunas de las cuales alcanzaron numerosas ediciones en pocos años. Por poner un ejemplo: la traducción de Lutero del Nuevo Testamento al alemán (1522) se agotó en tres meses y la traducción de su Biblia (1534) tuvo en vida de Lutero más de cuatrocientas ediciones de toda o de partes de ella.

\footnotetext{
גזר ממכלה צאן ואין בקר ברפתים 43.

${ }^{44}$ Commentaria, pág. 629. Posibles erratas tipográficas: «lloniese» por «lloviese», «seme» por «se me». En los Refranes de Hernán Núñez figura así: «Aora elasse, hasta que esta lana se me enhetrasse: aora llouiesse, hasta que la punta deste mi cuerno se me enmolleciesse».

45 פנה אל הרבה והנה למעט.

${ }^{46}$ Commentaria, pág. 676.

. וזריתי פרש על פניכם פרש חגיכם 47.

${ }^{48}$ Commentaria, pág. 850. Posible errata tipográfica por «a las».
} 
Las traducciones al español no se realizaron en territorio hispano. La Biblia de Ferrara (1553) y la Biblia del Oso, de Casiodoro de Reina (Basilea 1569), son traducciones llevadas a cabo por judíos y reformados españoles en el exilio.

Arias Montano no incluyó entre sus proyectos el traducir la Biblia al español. Y no es que no le interesaran las traducciones vernáculas, como demuestra el hecho de que, en su etapa de bibliotecario de El Escorial, se encargara de reunir manuscritos de las Biblias medievales romanceadas secuestradas por la Inquisición.

Pero Arias Montano tradujo, y tradujo mucho: al latín, los Profetas Primeros de la Biblia Políglota; corrigió la edición literal de Pagnino del Antiguo Testamento, y la de la Vulgata de Jerónimo del Nuevo Testamento, aunque no con la literalidad de la que hizo gala en los Prefacios.

Sin embargo, en sus Commentaria tradujo de nuevo al latín buena parte de los libros, algunos, como el de Jueces, prácticamente entero, por estar en desacuerdo con el texto de la versión Vulgata. Es aquí donde demostró, sin las constricciones que le imponían los textos de Pagnino y de la Vulgata -es decir, sin tener que partir de unas traducciones preestablecidas- sus cualidades de traductor y su gran fidelidad al hebreo.

En los pasajes difíciles recurrió a las lenguas modernas de Europa para esclarecer el sentido del texto. Se puede afirmar que su presunción de conocer diez lenguas ${ }^{49}$ no era gratuita.

Solo o con algunos colaboradores proveyó de versiones interlineares latinas a los textos originales de la Biblia Políglota. Incluyó al margen las raíces hebreas que podrían resultar difíciles, continuando así con los métodos pedagógicos, que ya habían sido utilizados en la Políglota Complutense.

Arias Montano reforzó esa finalidad pedagógica; de ahí su insistencia, como dice en el Prefacio a la traducción latina del Nuevo Testamento griego, en que el lector con poca preparación en las lenguas antiguas «en diez meses o incluso en menos tiempo, puede adquirir un conocimiento no escaso de las dos lenguas, griega y hebrea ${ }^{50}$. En el Prefacio de la traducción latina del Antiguo Testamento hebreo, afirma: «Estimamos que esta traducción va a tener gran utilidad no solamente para los estudiosos de la lengua hebrea, sino para los que desean conocer la fuerza hebrea y en latín

\footnotetext{
${ }^{49}$ Prefacios, pág. 57.

${ }^{50}$ Prefacios, pág. 75.
} 
la propiedad... si quieren dedicar un estudio constante a este aprendizaje, en el plazo de cuatro o a lo sumo seis meses adquieran el conocimiento de la lengua hebrea ${ }^{51}$. Y en ese mismo Prefacio, manifiesta su deseo de que los lectores «[...] aprendan al menos a leer hebreo, si desean sacar algún fruto de este libro solamente. Se trata de una tarea de tres o cuatro días, de la que nunca se arrepentirán ${ }^{52}$.

Recurrió al español en varias ocasiones en sus comentarios bíblicos. Topónimos, dichos, refranes. Buscó reflejar la sonoridad de la lengua original, consiguiendo, en ocasiones logros no superados por los traductores modernos al español. Por ejemplo, en la traducción de los topónimos se adelantó a versiones modernas como las de la Nueva Biblia española de Luis Alonso Schökel. Pensamos que los dichos y refranes que utiliza son de gran interés para la historia del español.

Al cerrar este análisis, creemos que es una lástima que sus profundos conocimientos de las lenguas originales, su sensibilidad lingüística respecto al español, su dominio de la geografía, historia, arqueología, la flora, la fauna y los realia bíblicos de Tierra Santa, su destreza en el uso de los giros de la lengua hebrea, de los modismos hebreos y castellanos, no le condujeran a una traducción propia de toda la Biblia al español.

De haber sido así, Arias Montano hubiera sido tal vez considerado como el mejor traductor de la Biblia al castellano.

Recibido: $16 / 03 / 2012$

Aceptado: 23/05/2012

${ }^{51}$ Prefacios, pág. 99.

${ }^{52}$ Prefacios, pág. 101. 